\title{
Bronchopulmonary Sequestration
}

National Cancer Institute

\section{Source}

National Cancer Institute. Bronchopulmonary Sequestration. NCI Thesaurus. Code

C97124.

A rare congenital abnormality of the lungs. It consists of a mass of lung parenchyma that does not communicate with the bronchial tree and receives its blood supply from the systemic circulation instead of the pulmonary circulation. 